\title{
Simultaneous Rp-Hplc Method For Determination Of Betamethasone Dipropionate And Tolnaftate In Combined Semisolid Formulation
}

\section{Radhika.V ${ }^{* 1}$, T.Ramesh ${ }^{2}$}

${ }^{1}$ Department of Pharmaceutical Analysis, Browns College of Pharmacy, Khammam, Telangana, India.

${ }^{21}$ Department of Pharmaceutical Analysis, Tirupur Kalaimagal College of Pharmacy, Tirupur, Tamilnadu, India

\section{Correspondence Author}

V.Radhika

Department of Pharmaceutical Analysis

Browns College of Pharmacy

Khammam,

Telangana, India

Mobile: 6302648437

E.Mail: satishchandrano.1@gmail.com 


\begin{abstract}
:
A new RP-HPLC method was developed for selective and simultaneous determination of betamethasone dipropionate and tolnaftate in combined semisolid formulation containing other components. Further, the proposed method was validated for linearity, precision (system precision, method precision, intermediate or inter-day precision), accuracy, stability in analytical solution, robustness or system suitability and ruggedness. The developed method exhibited the best results in terms of the aforesaid validation parameters. The other components and additives did not interfere in their determinations. The method was found to be selective, simple, economical, accurate, reproducible, rapid and reliable for routine estimation purpose of these drugs in combined semisolid formulations.
\end{abstract}

Key-words: Betamethasone dipropionate, tolnaftate, RP-HPLC, semisolid formulation. 


\section{INTRODUCTION}

Betamethasone dipropionate is chemically 9- fluoro $11 \beta, 17,21$-trihydroxy-16 $\beta$ methylpregna-1,4- diene-3,20-dione 17,21-dipropionate and it belongs to the class of adrenocortical steroid and used as topical corticosteroid in treatment of different skin disorders. Tolnaftate is O-naphthalen-2-yl methyl (3-methyl phenyl) thiocarbamate and it belongs to the class of antifungal and used topically in the treatment or prophylaxis of superficial dermatophyte infections ${ }^{1,2}$.

The official methods for determination of betamethasone dipropionate in different pharmaceutical dosage forms are prescribed in the United States Pharmacopoeia (USP). USP 29 prescribes RP-HPLC method for determination of betamethasone dipropionate in cream, lotion and ointment, using a reversed phase L1 column with particle size 3-10 $\mu \mathrm{m}$, acetonitrile as mobile phase, beclomethasone dipropionate RS as internal standard and UV detection at 254 or $240 \mathrm{~nm}$. USP 30 prescribes spectrophotomeric determination for determination of tolnaftate in cream and gel after appropriate extraction at $258 \mathrm{~nm}$. The British Pharmacopoeia (2005) however, does not include formulations of betamethasone dipropionate and tolnaftate. Different liquid chromatographic methods have been reported for determination of betamethasone valerate alone or in combination in different formulations ${ }^{3,4}$. But no method has been developed so far for the combination of betamethasone dipropionate and tolnaftate which are widely employed in combination along with other antimicrobials in various topical skin care formulations. Therefore, it was found worthwhile to develop an appropriate validated liquid chromatographic method for simultaneous estimation of betamethasone dipropionate and tolnaftate in combined multicomponent semisolid formulations. A successful attempt was made in this context and the present paper aims to report the same.

\section{EXPERIMENTAL}

\section{Reagents and Chemicals:}

The solvents (acetonitrile, methanol and water) were of HPLC grade standard. The standard samples of betamethasone dipropionate and tolnaftate were obtained from Glenmark Pharmaceuticals Ltd., Nashik, India. Marketed formulation of Quadridus ointment (Zydus Cadila) was procured from local market.

\section{Chromatographic conditions:}

A gradient HPLC (Shimadzu LC2010CHT) with serial dual plunger pump; analytical column: Inertsil ODS, $150 \times 4.6 \mathrm{~mm}$, particle size $5 \mu \mathrm{m}$; flow rate: $1.2 \mathrm{ml} / \mathrm{min}$; column 
temperature : ambient; detection : UV $240 \mathrm{~nm}$; data processing software: LCsolution Ver. 1.2 .

\section{Mobile phase:}

A filtered and degassed mixture of Acetonitrile, methanol and water in the ratio of 60:15:25 was employed in the study.

\section{Preparation of the standard solutions:}

About $30.5 \mathrm{mg}$ of standard betamethasone dipropionate was weighed accurately and transferred to a $50 \mathrm{ml}$ volumetric flask, dissolved by shaking and made the volume up to the mark with acetonitrile (denoted as standard A). About $20 \mathrm{mg}$ of standard tolnaftate was weighed and transferred to a $10 \mathrm{ml}$ volumetric flask, dissolved by shaking and made the volume up to the mark with acetonitrile (denoted as standard B).

\section{Mixed standard preparation:}

$1.0 \mathrm{ml}$ of standard solution A and $5.0 \mathrm{ml}$ of standard solution B were taken and transferred to a $25 \mathrm{ml}$ volumetric flask, mixed well and made the volume up to the mark with acetonitrile. Hence, the final concentrations of betamethasone dipropionate and tolnaftate were 24.4 $\mu \mathrm{g} / \mathrm{ml}, 400 \mu \mathrm{g} / \mathrm{ml}$ respectively.

\section{Preparation of the sample solution:}

The ointment procured from market contained gentamicin sulphate and clioquinol along with the analytes under present estimation. There was no types of pretreatment and prior separation of individual drugs. The ointment equivalent to $2.44 \mathrm{mg}$ of betamethasone dipropionate and $40 \mathrm{mg}$ of tolnaftate was weighed and transferred to a $100 \mathrm{ml}$ volumetric flask, $60 \mathrm{ml}$ acetonitrile was added into it and warmed to just melt, sonicated (PCI 6.5 lit) for 20 minutes, cooled and made the volume up to the mark with acetonitrile. The resultant solution was filtered with Whatmann filter paper (No.1), and the filtrate was collected for use in the study discarding the first portions of the filtrate.

\section{Chromatographic procedure:}

$10 \mu \mathrm{L}$ of the mixed standard preparation and assay (sample) preparation were separately injected into the chromatograph, the chromatograms were recorded, and the responses for the major peaks were measured. The run time was approximately 12 mins.

\section{Validation of HPLC method}

In order to confirm method suitability during routine quality control use, the proposed method was checked critically for the following validation characteristics as per ICH guidelines $^{5-9}$.

\section{Linearity:}


Linearity for Betamethasone dipropionate and tolnaftate was determined in the concentration range 70 to $130 \%$ of working concentration of standard. The peak area responses were plotted against the corresponding concentrations and the $\mathrm{r} 2$ values were calculated $^{10}$.

\section{Precision}

\section{System precision:}

Six replicate injections of mixed standard solution at the concentration of betamethasone dipropionate $24.4 \mu \mathrm{g} / \mathrm{ml}$ were injected into HPLC system. Similarly six replicate injections of mixed standard solution at the concentration of tolnaftate $400 \mu \mathrm{g} / \mathrm{ml}$ were injected into HPLC system The percentage relative standard deviations ( \% RSD) in each case were calculated ${ }^{11}$.

\section{Method precision:}

Six replicate samples of betamethasone dipropionate and tolnaftate from marketed formulation (ointment) were analyzed as per the method. The mean percentage of drug content as per label claim and $\%$ RSD were calculated in each case ${ }^{12}$.

\section{Intermediate precision or inter-day precision:}

The intermediate or inter-day precision of the method was determined by six replicate analysis of betamethasone dipropionate and tolnaftate from sample, as per the proposed method by different instruments (Shimadzu LC2010CHT and Shimadzu SPD-10 A VP), by same analyst on different days. The average drug content and the \% RSD were calculated in each case $^{13}$.

\section{Accuracy (recovery studies):}

Recovery studies were performed by standard addition method at three levels i.e. $80 \%, 100 \%$ and $120 \%$. Known amounts of standard betamethasone dipropionate and tolnaftate were added to pre-analyzed samples and they were subjected to proposed HPLC method. Results of recovery studies are shown in Table 1 .

\section{Stability of analytical solution:}

The sample solution was prepared and injected into the system and analyzed as per the proposed method, initially and at $4 \mathrm{~h}$ time intervals up to $24 \mathrm{~h}$, at room temperature and at $8{ }^{\circ} \mathrm{C}^{14}$.

\section{Robustness (system suitability):}

The robustness study was done by making small changes in the optimized method parameters as indicated in Table 2 and 3. Results are also shown there ${ }^{15}$.

\section{Ruggedness:}


The ruggedness study was done by the two analysts by using the proposed method by same instrument on same day. The \% RSD for each analyst for each drug were calculated

\section{RESULTS AND DISCUSSION}

In linearity study, The graphical representation of data proves that betamethasone dipropionate demonstrate linearity in the range of $17.92 \mu \mathrm{g}$ to $33.28 \mu \mathrm{g}$ with $\mathrm{r} 2$ value 0.9992 and tolnaftate demonstrate linearity in the range of $280 \mu \mathrm{g}$ to $520 \mu \mathrm{g}$ with $\mathrm{r} 2$ value 0.9970 .

In system precision study, the \% RSD for betamethasone dipropionate and tolnaftate were found to be 0.58 and 0.10 respectively. The $\%$ RSD observed on the replicate indicates the precision of the system.

In method precision study, the mean $\%$ drug content for betamethasone dipropionate and tolnaftate were found to be $103.56 \%$ and $103.13 \%$ respectively. The $\%$ RSD for betamethasone dipropionate and tolnaftate were found to be 1.8 in both cases. The results indicate that the method is validated for method precision. No interference form other components or excipients was found during determination. In intermediate or inter-day precision study, the mean $\%$ drug content for betamethasone dipropionate and tolnaftate were found to be 103.59 and 102.75 respectively. The \% RSD for betamethasone dipropionate and tolnaftate were found to be 1.19 and 1.25 respectively. There is no significant difference by same analyst by different instruments on different day. Therefore the intermediate or interday precision of the method can be considered to be acceptable.

In accuracy or recovery studies, the results are shown in Table 1 . The overall $\%$ of recovery and \% RSD for betamethasone dipropionate and tolnaftate in marketed formulation indicated that there is no significant difference in percentage of recovery. Therefore, accuracy of the method considered acceptable as it was well within 98 to $102 \%$.

Table 1: Result of recovery studies

\begin{tabular}{|l|l|l|l|}
\hline Drugs & Recovery levels & Mean \% of recovery & \% RSD \\
\hline $\begin{array}{l}\text { Betamethasone } \\
\text { dipropionate }\end{array}$ & $80 \%$ & 98.77 & 0.16 \\
\cline { 2 - 4 } & $100 \%$ & 99.48 & 0.02 \\
\cline { 2 - 4 } & $120 \%$ & 98.8 & 0.33 \\
\hline Tolnaftate & $80 \%$ & 100.11 & 0.21 \\
\cline { 2 - 4 } & $100 \%$ & 100.68 & 0.15 \\
\hline
\end{tabular}




\begin{tabular}{|l|l|l|l|}
\hline & $120 \%$ & 100.16 & 0.1 \\
\hline
\end{tabular}

Instability studies of analytical solution, Betamethasone dipropionate in analytical solution was found to be stable up to $20 \mathrm{hrs}$ at room temperature and up to $24 \mathrm{hrs}$ at $8{ }^{\circ} \mathrm{C}$. Tolnaftate was found to be stable upto $24 \mathrm{hrs}$ at room temperature as well as at $8{ }^{\circ} \mathrm{C}$.

In the robustness or system suitability study, there was no significant impact on the \% RSD and tailing factor. The results of the robustness study also indicated that the method is robust and is unaffected by small variations in the chromatographic conditions.

Table 8: Robustness studies for Betamethasone dipropionate.

\begin{tabular}{|l|l|l|l|}
\hline Parameters & Tailing factor & $\begin{array}{l}\text { Theoretical } \\
\text { plates }\end{array}$ & $\begin{array}{l}\text { \% RSD of } \\
\text { replicates }\end{array}$ \\
\hline Change in wavelength $-5 \mathrm{~nm}$ & 1.2 & 2567.808 & 1.38 \\
\hline Change in wavelength $+5 \mathrm{~nm}$ & 1.16 & 2316.743 & 0.42 \\
\hline Change in column temperature $-5^{\circ} \mathrm{C}$ & 1.37 & 2786.214 & 1.86 \\
\hline Change in column temperature $+5^{\circ} \mathrm{C}$ & 1.37 & 2851.398 & 0.41 \\
\hline Change in mobile phase $-2 \%$ (Acetonitrile) & 0.86 & 1754.833 & 1.99 \\
\hline Change in mobile phase $+2 \%$ (Acetonitrile) & 1.18 & 2232.18 & 0.25 \\
\hline Change in mobile phase $-2 \%$ (Methanol) & 1.07 & 2298.606 & 2.0 \\
\hline Change in mobile phase $+2 \%$ (Methanol) & 1.09 & 2129.647 & 0.35 \\
\hline Change in flow rate $-10 \%$ & 1.26 & 3044.945 & 1.9 \\
\hline Change in flow rate $+10 \%$ & 1.73 & 2562.406 & 1.04 \\
\hline
\end{tabular}

Table 9: Robustness studies for Tolnaftate.

\begin{tabular}{|l|l|l|l|}
\hline Parameter & $\begin{array}{l}\text { Tailing } \\
\text { factor }\end{array}$ & $\begin{array}{l}\text { Theoreticl } \\
\text { plates }\end{array}$ & $\begin{array}{l}\text { \% RSD of } \\
\text { replicates }\end{array}$ \\
\hline Change in wavelength $-5 \mathrm{~nm}$ & 1.15 & 2795.301 & 0.31 \\
\hline Change in wavelength $+5 \mathrm{~nm}$ & 1.10 & 2487.257 & 0.26 \\
\hline Change in column temperature $-5^{\circ} \mathrm{C}$ & 1.36 & 3575.891 & 0.3 \\
\hline Change in column temperature $+5^{\circ} \mathrm{C}$ & 1.35 & 3388.96 & 0.39 \\
\hline
\end{tabular}




\begin{tabular}{|l|l|l|l|}
\hline Change in mobile phase $-2 \%$ (Acetonitrile) & 1.05 & 2138.911 & 0.16 \\
\hline Change in mobile phase $+2 \%$ (Acetonitrile) & 1.15 & 2435.074 & 0.03 \\
\hline Change in mobile phase $-2 \%$ (Methanol) & 1.07 & 2974.22 & 0.1 \\
\hline Change in mobile phase $+2 \%$ (Methanol) & 1.05 & 2370.486 & 0.24 \\
\hline Change in flow rate $-10 \%$ & 1.25 & 3703.879 & 0.06 \\
\hline Change in flow rate $+10 \%$ & 1.83 & 3434.879 & 0.3 \\
\hline
\end{tabular}

In ruggedness study, the $\%$ RSD for analyst-I was $0.1088 \%$ for betamethasone dipropionate and $0.1078 \%$ for tolnaftate and for analyst-II was $0.3208 \%$ for betamethasone dipropionate and $0.7329 \%$ for tolnaftate, respectively. It is also a type of intermediate precision study. The results of ruggedness study was found to be satisfactory.

\section{ACCURACY}

\section{For accuracy $80 \%$}

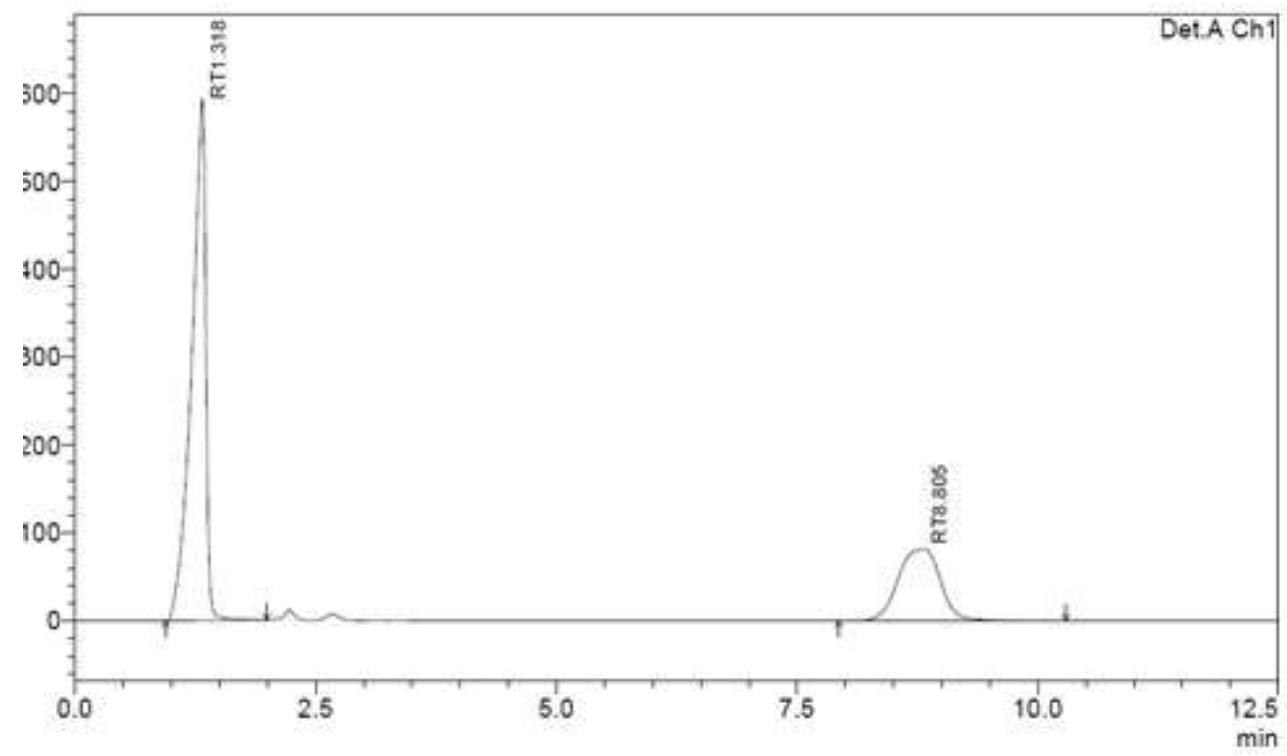

Fig-7: Chromatogram Showing Accuracy-80\% Injection-1

\section{For accuracy $100 \%$}




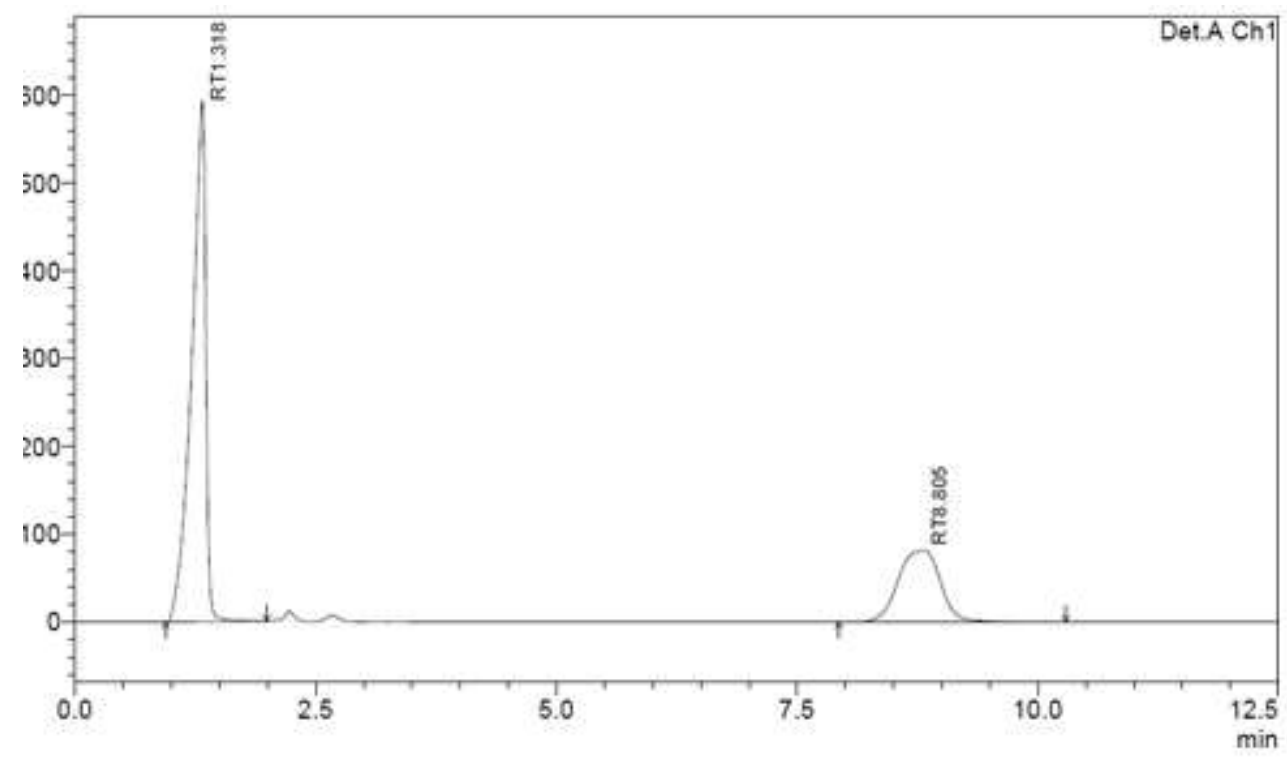

Fig-8: Chromatogram Showing Accuracy-100\% Injection-1

For accuracy $120 \%$

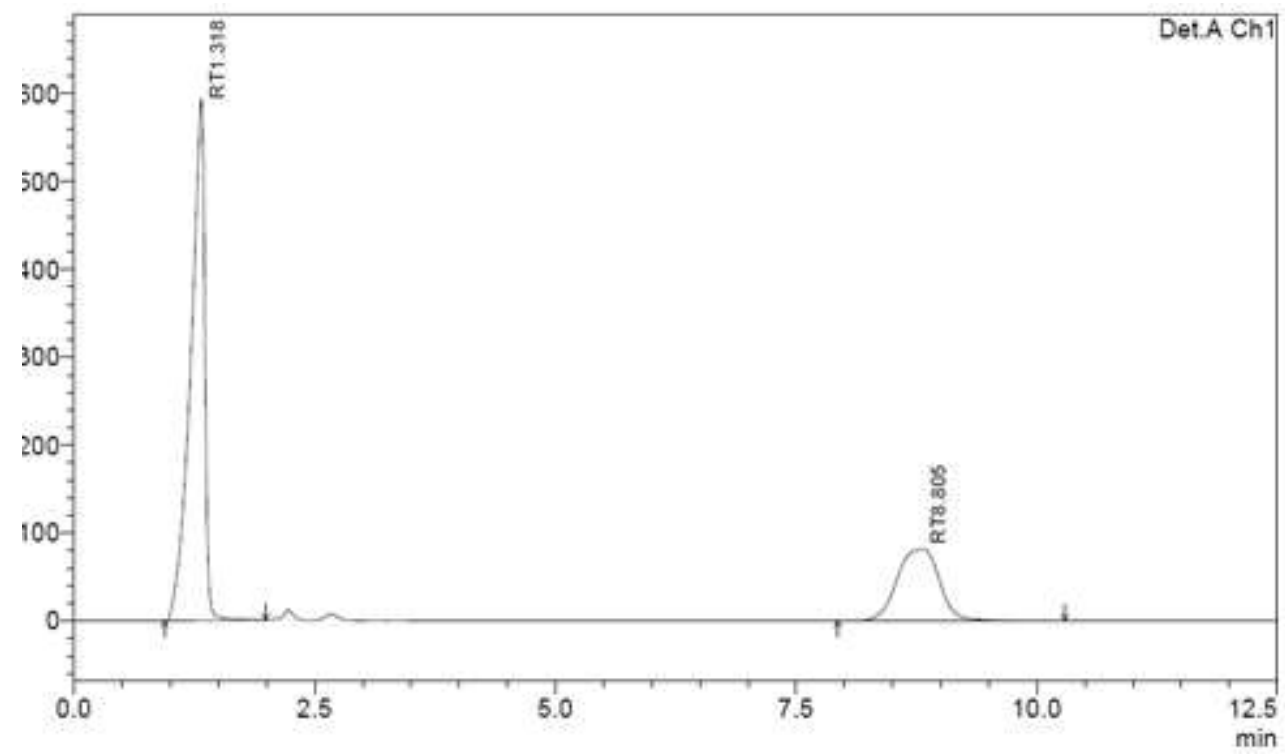

Fig-9: Chromatogram Showing Accuracy-120\% Injection-1

\section{LINEARITY}




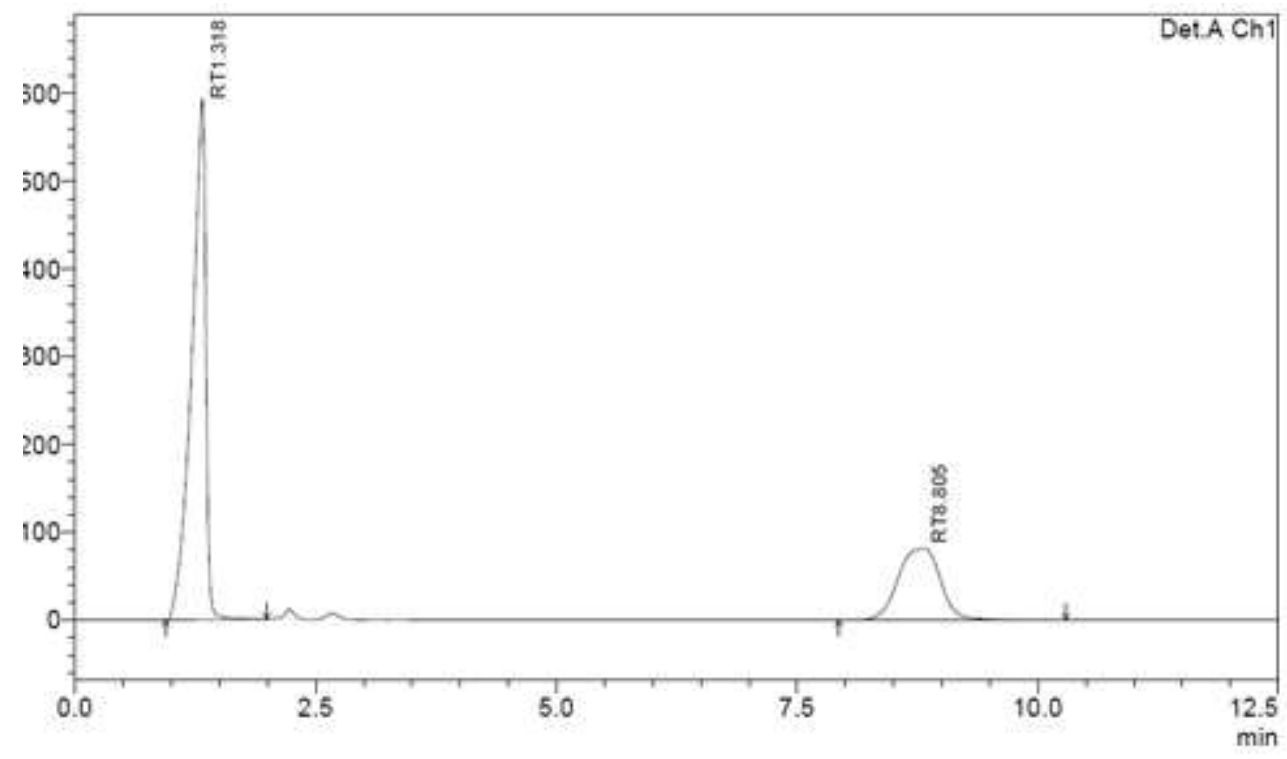

Fig-10: Chromatogram showing Linearity Level-1 (30ppm)

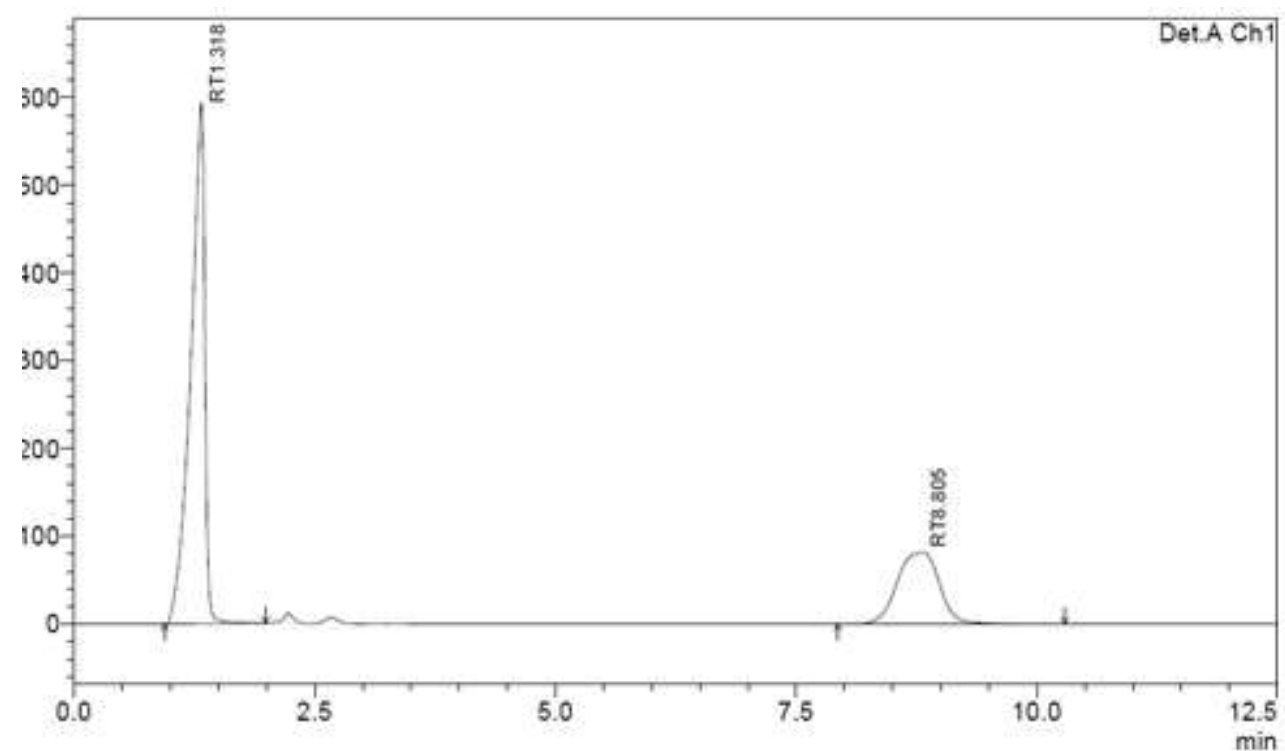

Fig-11: Chromatogram showing Linearity Level-2 (40ppm) 


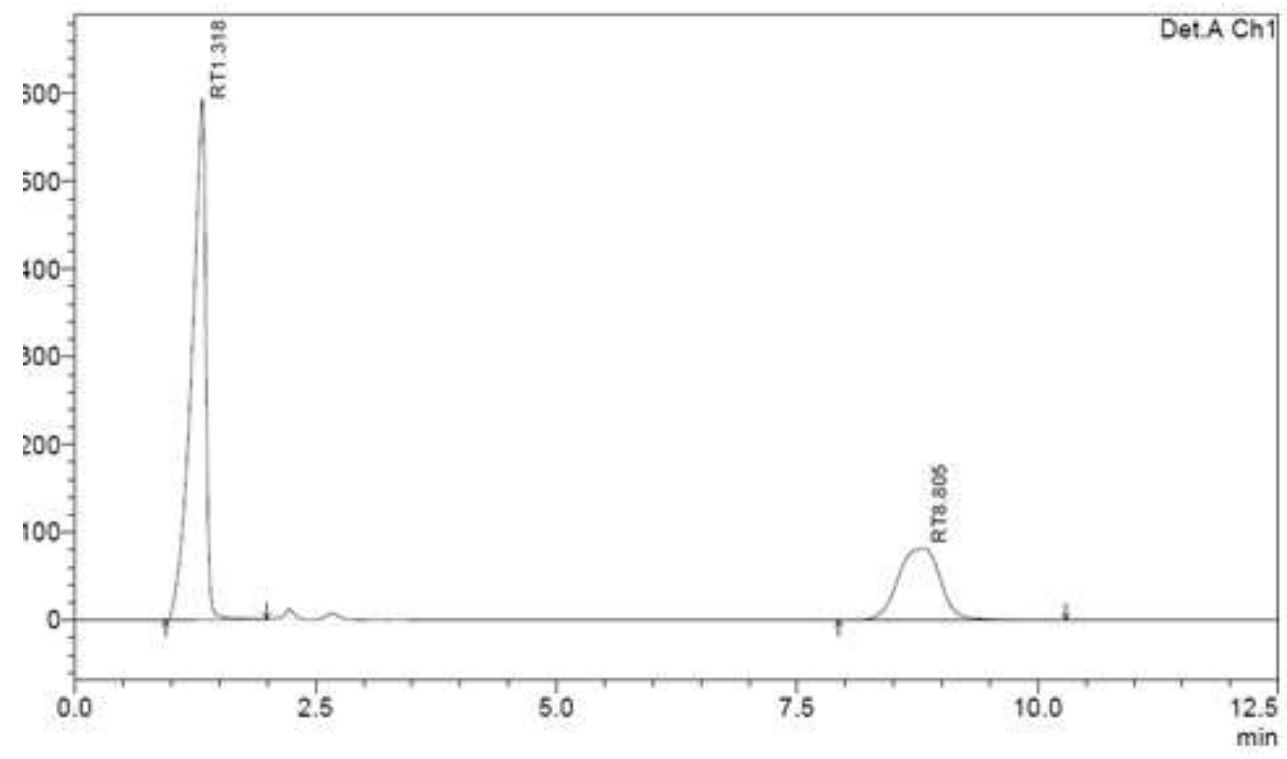

Fig-12: Chromatogram showing Linearity Level-3 (50ppm)

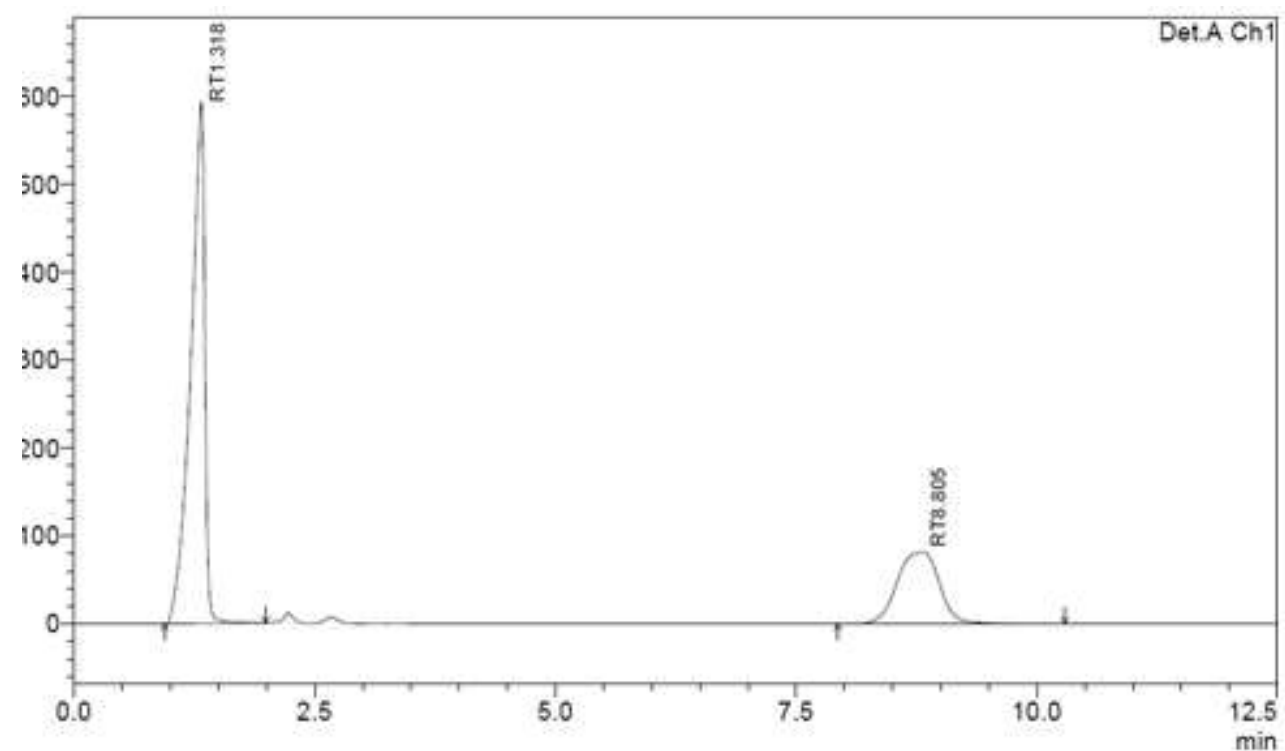

Fig-13: Chromatogram showing Linearity Level-4 (60ppm) 


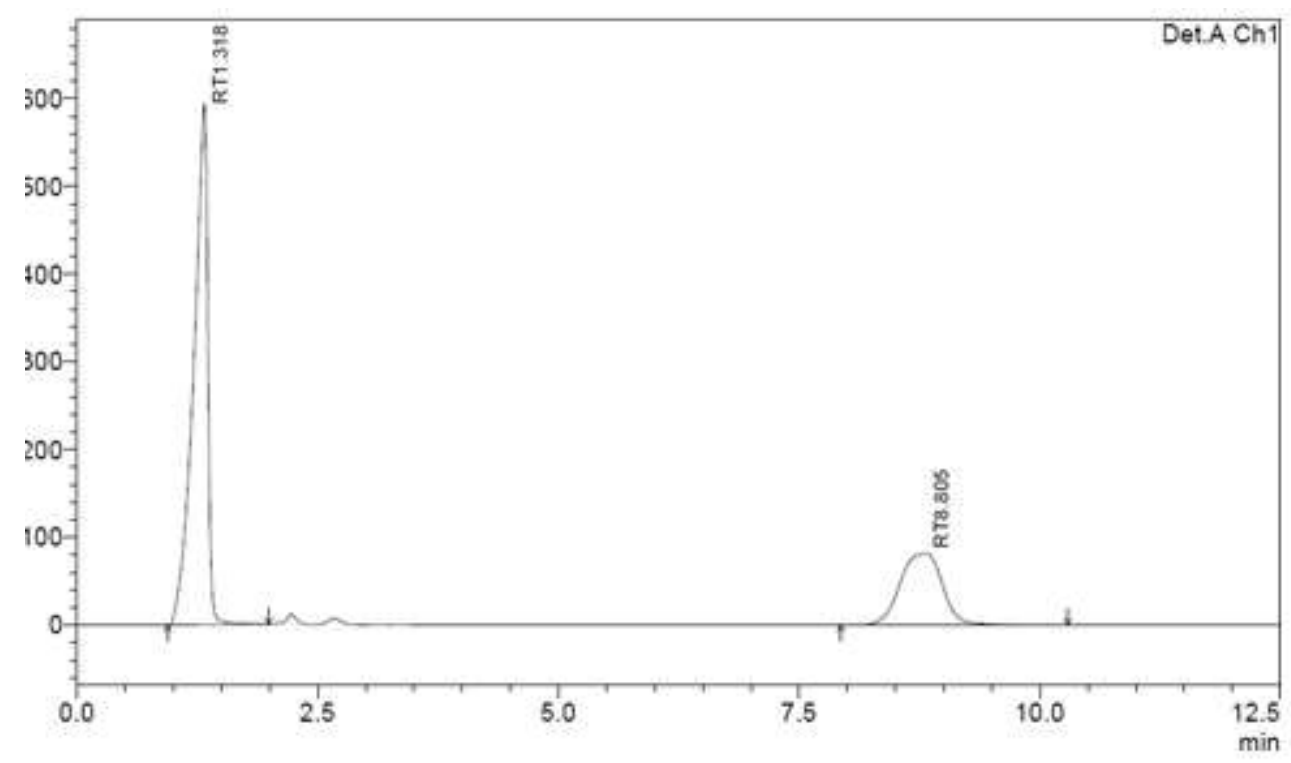

Fig-14: Chromatogram showing Linearity Level-5 (70ppm)

\section{Robustness of the Method:}

The Robustness was carried out for the flow rate alterations from $0.9 \mathrm{ml} / \mathrm{min}$ to $1.1 \mathrm{ml} / \mathrm{min}$ and mobile phase ratio from more to less organic ratio.

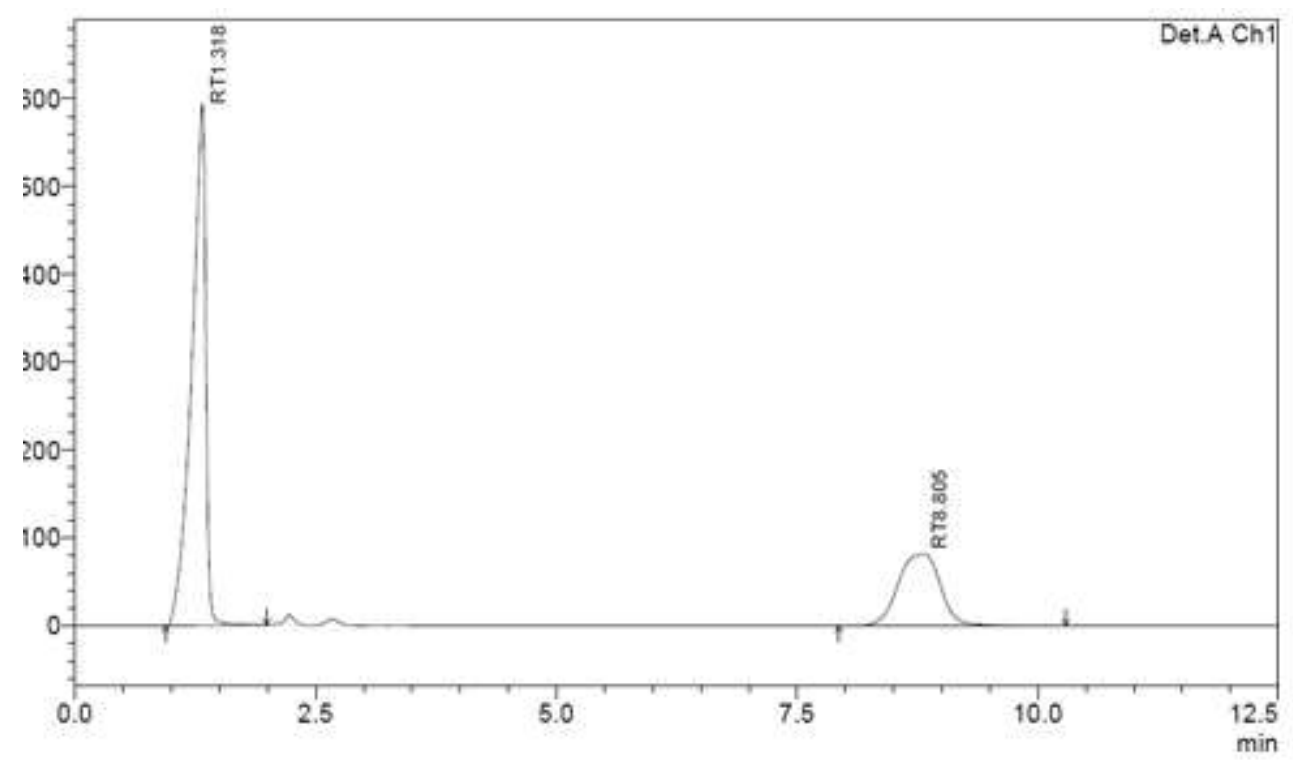

Fig-15: Chromatogram showing flow rate $1.1 \mathrm{ml} / \mathrm{min}$ 


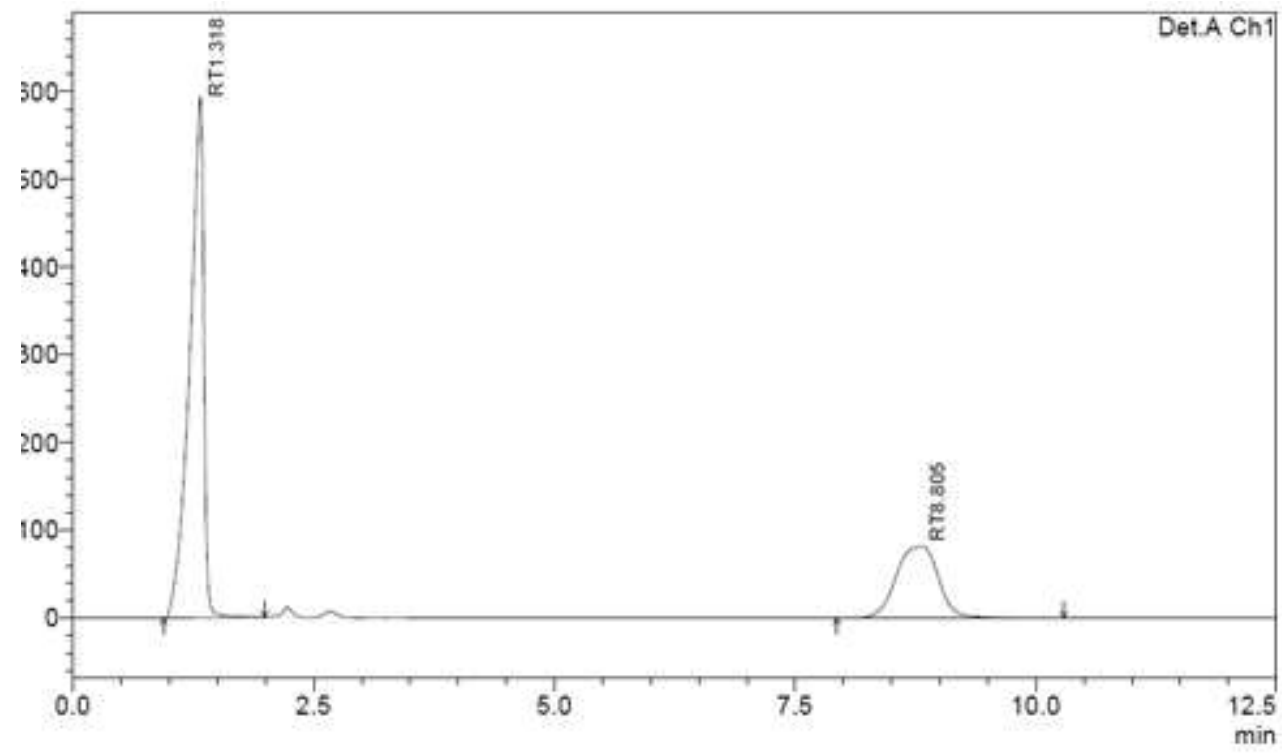

Fig-16: Chromatogram showing flow rate $0.9 \mathrm{ml} / \mathrm{min}$ 


\section{CONCLUSION}

Hence, it can be concluded that the newly developed RP-HPLC method was found to be simple, rapid, cost-effective, linear, accurate, precise and robust over the specified range; and selective for Betamethasone dipropionate and Tolnaftate without any interference from other components or additives. This method can be employed conveniently, reliably and successfully for the estimation of Betamethasone dipropionate and Tolnaftate for routine quality control and stability studies in combined multicomponent semisolid formulations.

\section{REFERENCES}

ChandraNathSaha and Sanjib Bhattacharya, A validated simultaneous Rp-HPLC method, International Journal of c Chem Tech Research, July 2009,vol1, no.3, p 671-674.

2.Ermer J., Miller J. H. M. Method Validation in Pharmaceutical Analysis: A Guide to Best Practice. Wiley-VCH-Verlag-GmbH \& Co., Weinheim, 2005

3. C. Sweetman. Martindale the complete drug reference, 29th edition, Pharmaceutical Press, London, 2005, p. 416.3 and 1093.3.

4.Merck index an encyclopedia of chemicals drugs and biologicals, $14^{\text {th }}$ edition, White House Station NJ, USA, 2006, p. 1438 and 9519.

5.Sethi P.D HPLC Quantitative analysis of drugs in pharmaceutical formulations, $1^{\text {st }}$ edition, CBS publishers and distributors, New Delhi: 2007, Vol II P.121, 469, 473, 475, 477, 479, 481,483 .

6.Unites States Pharmacopoeia 31 NF26, Asian edition, 2008, Vol-III, p. 3211-3212 and 3433-3434.

7.Sethi P.D HPTLC Quantitative analysis of pharmaceutical formulations, $1^{\text {st }}$ edition, CBS publishers and distributors, New Delhi: 1996 p.410-413.

8.Shou M, Galinada WA, Wei YC, Tang Q, Markovich RJ, Rustum AM. Development and validation of a stability-indicating HPLC method for simultaneous determination of salicylic acid, betamethasone dipropionate, and their related compounds in Diprosalic Lotion.J Pharm Biomed Anal. 2009Oct15;50(3):356-61.Epub 2009 May 23. Pub Med PMID:19545962. 
9.A validated simultaneous RP-HPLC method for determination of Betamethasone dipropionate and tolnaftate in combined semisolid formulation.Chandranath Saha and sanjib bhattacharya.

10.Indian pharmacopoeia, Indian pharmacopoeia commission Ghaziabad: 2010, Vol-III, P2089 and 2238-2240. 1998;94:557-72.

11. Barnes PJ. Therapeutic strategies for allergic diseases. Nature. 1999;402(Suppl 6760):B31-8.

12. Haynes RC., Jr .Thyroid and antithyroid drug. In: Gilman AG, Rall TW, Nies AS, Taylor P, editors. Goodman and Gilman's the pharmacological basis of therapeutics. 8th ed. New York: Pergamon Press; 1990. p. 1361-83.

13. Genotoxic and Carcinogenic Impurities in Drug Substances and Products: Recommended Approaches. FDA Center for Drug Evaluation and Research. Guidance for Industry (Draft) 2008 Dec 03;

14. Roy J. Pharmaceutical Impurities-A Mini-Review. AAPS PharmSciTech. 2002;3(2):E6.

15. Ueda CT, Shah VP, Derdzinski K, Ewing G, Flynn G, Maibach H, et al. Topical and Transdermal Drug Product-Stimuli to the revision process. Pharmacopeial Forum. 2009;35: p 750-64. 